\title{
Do PROBLEMA DO ESSENCIALISMO A OUTRA MANEIRA DE SE FAZER POLÍTICA: RETOMANDO O POTENCIAL TRANSFORMADOR DAS POLÍTICAS DE DIFERENÇA
}

\author{
Léa Tosold
}

\begin{abstract}
RESUMO
Este artigo visa retomar e fazer uma avaliação crítica do debate sobre as políticas de diferença travado entre teóricas políticas feministas de tradição liberal. Após explicitar as estratégias apontadas nesse debate para tentar legitimar a politização de sujeitos coletivos em face do problema do essencialismo, argumenta-se que 0 excessivo foco na relação entre essencialismo e conceitualização de grupos sociais ofuscou o vínculo do projeto de politização de diferenças com o questionamento do próprio fazer político. Assim, sob a perspectiva de que a politização de diferenças está transformando - e não inviabilizando - o funcionamento da comunidade política e a possibilidade de efetiva justiça social, avalia-se como os projetos políticos de Anne Phillips e Iris Marion Young evidenciam novos caminhos para
\end{abstract}

\footnotetext{
${ }^{1}$ Mestre em letras, filosofia e ciência política pela Universidade de Viena, mestre em filosofia política pela Universidade de York e doutoranda em ciência política pela Universidade de São Paulo e pela Universidade de Brasília. Sua pesquisa enfoca a relação entre política e (re)produção de desigualdades raciais, de gênero e de classe. End. Eletrônico: leatosold@gmail.com
} 
reconfigurar a esfera política de uma maneira transformadora das desigualdades estruturais.

Palavras-chave: Políticas de diferença. Essencialismo. Desigualdades de gênero. Iris Marion Young. Anne Phillips.

\section{FROM ESSENTIALISM TO ANOTHER WAY OF DOING POLITICS: RESUMING THE TRANSFORMATIVE POTENTIAL OF THE POLITICS OF DIFFERENCE Abstract}

This article aims at resuming and critically scrutinizing the debate on the politics of difference taken among liberal feminist political theorists. Firstly, I shall provide an overview of theoretical attempts to legitimate the politicization of collectivebased subjects taking into account the problem of essentialism. Then I will argue that an exclusive focus on the relationship between essentialism and the conceptualization of collective-based subjects tends to overshadow the relationship between the politicization of differences and a new way of doing politics. I will defend the view that the politicization of differences is transforming rather than undermining the functioning of the polity and the possibility of real social justice. I shall evaluate the works of Anne Phillips and Iris Marion Young as offering new ways of reshaping the political sphere in order to enable proper institutional action against structural inequalities.

Keywords: Politics of difference. Essentialism. Gender inequalities. Iris Marion Young. Anne Phillips.

s políticas de diferença² foram, ao longo dos últimos anos, tema de intenso
debate entre teóricas políticas feministas de tradição liberal. Em termos
gerais, pode-se afirmar que, pouco a pouco, o entusiasmo que caracterizou

${ }^{2}$ Por políticas de diferença ou politização de diferenças se entende a inclusão de grupos sociais que sofrem de desvantagens estruturais na sociedade com base em fatores moralmente arbitrários, como, por exemplo, gênero e raça, na esfera pública (comp. com I. M. YOUNG, 1990, p. 42-8). É importante observar que, no presente artigo, políticas de diferença não devem ser confundidas com multiculturalismo, cuja defesa por reconhecimento de entidades coletivas para fins de representação política não se baseia em reivindicações por justiça, mas no valor da diversidade per se, visto que afiliações de grupo são consideradas fundamentais para o desenvolvimento particular dos indivíduos. Sobre multiculturalismo, ver C. Taylor (1992, p. 25-73) e W. Kymlicka (1996).

Do PROBLEMA DO ESSENCIALISMO A OUTRA MANEIRA DE SE FAZER...

L. TOSOLD $\bullet 167$ 
o surgimento do projeto de politização de sujeitos coletivos foi arrefecendo. No plano teórico, a tendência tem sido a de reconhecer os limites das políticas de diferença - dado o problema do essencialismo que parece inevitavelmente acompanhar o processo de politização de atores coletivos - e buscar alternativas que as suplantem.

Ao mesmo tempo, no entanto, pode-se também perceber no debate uma grande resistência em abrir mão das políticas de diferença, como se algo muito importante fosse perdido quando estas são deixadas de lado. Isso porque justamente as categorias teóricas que legitimam as políticas de diferença são as que tornam possível também entender e desafiar as estruturas que geram desigualdades estruturais (PHILLIPS, 1992, p. 13). Afinal, seria possível identificar e combater desigualdades estruturais baseadas em gênero sem lançar mão do próprio conceito de gênero enquanto categoria política legítima?

Assim, o debate passou a centrar-se em torno da seguinte questão: é possível manter gênero enquanto categoria teórica viável sem incorrer em essencialismo? Como veremos, tal dilema está longe de haver sido resolvido. Mais do que isso, o debate se encontra polarizado. Por um lado, certas teóricas rejeitam totalmente o projeto de politização de diferenças com base na "infalível crítica" do essencialismo (FUSS, 1989, p. xi). Por outro lado, algumas teóricas argumentam que a mera rejeição das políticas de diferença com base no problema do essencialismo acaba por justificar estagnação política em relação ao problema estrutural de desigualdades de gênero. Persuadidos de que "feministas hoje não podem se dar ao luxo de não serem essencialistas" (BRAIDOTTI, 1994, p. 177 apud LLOYD, 2005, p. 65, grifos no original), muitos estudiosos preocupados com a perda da categoria gênero para fins políticos passaram a concentrar esforços em demonstrar que essencialismo, em si, não é necessariamente negativo.

No que segue, pretende-se retomar os termos desse debate sobre a politização de diferenças a partir de uma perspectiva crítica. Ao revelar o desenvolvimento da discussão travada por teóricas políticas feministas sobre a relação entre as políticas de diferença e o problema do essencialismo, argumentar-se-á que a maneira como se vincula essencialismo exclusivamente a um problema de conceitualização de grupos - tanto na tentativa de legitimar a inclusão de atores coletivos na esfera pública sem incorrer em essencialismo quanto assumindo-o estrategicamente para fins políticos - estancou o potencial transformador do projeto de politização de diferenças. Isso porque, conforme veremos, o enfoque em uma conceitualização 
não essencialista de grupos sociais como forma de legitimar as políticas de diferença ofusca sua relação intrínseca com o questionamento do próprio fazer político. As políticas de diferença passam a ser percebidas como mero instrumento não ideal em uma configuração política já preestabelecida de antemão. Como consequência, observa-se - para além do crescente descrédito das políticas de diferença como um todo em teoria política - uma falta de questionamento dos mecanismos através dos quais o próprio fazer político acaba por (re)produzir desigualdades estruturais.

Assim, sob a ótica de que o projeto de politização de diferenças requer outro fazer político que seja capaz de dar conta da superação de desigualdades estruturais, propõe-se, na parte final deste artigo, avaliar como os projetos políticos de Anne Phillips e Iris Marion Young evidenciam novos caminhos para reconfigurar a esfera política de uma maneira transformadora das desigualdades estruturais.

\section{ESSENCIALISMO E POLITIZAÇÃO DE DIFERENÇAS}

Considerando que essencialismo, como Diana Fuss observa, é "um dos poucos termos no vocabulário da teoria política contemporânea tão persistentemente difamados, tão pouco interrogados e tão previsivelmente invocados como expressão de crítica infalível" (FUSS, 1989, p. xi), faz-se necessário perscrutar o que é essencialismo e de que maneira o projeto de politização de diferenças na forma de representação institucionalizada de grupos sociais é posto em questão pela sua presença.

Essencialismo refere-se à necessidade de estabilizar determinados grupos sociais enquanto sujeitos políticos. Ou seja, o processo de essencialização procura garantir a legitimidade da representação política de determinado grupo estabelecendo uma fronteira nítida que torne possível distinguir seus membros na sociedade como um todo. Esse processo engendra um grave problema: leva ao 'congelamento' e à descontextualização de identidades e diferenças como se fossem entidades fixas, visto que impõe a partir da esfera política uma visão única do que as distingue. 0 essencialismo dá margem, portanto, ao surgimento de aspirações de cunho totalitário para fins de estabilização política, pois tende a eliminar a partir da própria esfera pública qualquer outra interpretação possível do que caracteriza a diferença ou a identidade em questão. Dessa maneira, argumenta-se que qualquer tentativa de definir um grupo com fins políticos acaba por incorrer em pelo menos um dos seguintes problemas: (a) o de reduzir a afiliação a um grupo 
ao "genetic makeup" (BENHABIB, 2002, p. 73) que aparentemente o caracteriza, e (b) o de impor uma identidade e interesses específicos como condição para a afiliação ao grupo.

0 trecho acima, ademais de explicitar o que éessencialismo, define também 0 argumento mais comumente utilizado para se criticar as políticas de diferença, o qual assume que a inclusão de sujeitos coletivos na esfera pública implica necessariamente essencialismo (e será principalmente com base nessa crítica que, como veremos mais adiante, os teóricos favoráveis às políticas de diferença se concentrarão em tentar demonstrar que não é necessária a estabilização prévia dos grupos a fim de que sejam inseridos na esfera pública). No entanto, não explicita como o problema do essencialismo, para além da viabilidade de execução das políticas de diferença, também coloca em questão os motivos pelos quais, em teoria, passou-se a vislumbrar a necessidade de um projeto de politização de diferenças. Eis o que veremos a seguir.

0 projeto de politização de diferenças aparece, na teoria política, como resposta a pelo menos dois problemas centrais encontrados na maneira como a tradição liberal lida com o tipo de desigualdade estrutural que se origina com base em fatores moralmente arbitrários, como gênero, raça etc. 0 primeiro fundamenta-se na crítica ao ideal de imparcialidade na esfera pública proposto pelo liberalismo, acusado de legitimar a perpetuação de desigualdades de gênero ao esconder, sob a máscara de um suposto universalismo, a parcialidade que de fato rege os processos de deliberação política. Em resumo, argumenta-se que, no liberalismo, 0 apelo aos valores imparciais que supostamente regem as instituições políticas legitima uma espécie de "hierarquia autoritária" (YOUNG, 1990, p. 10) no processo de deliberação política, permitindo que resoluções sejam tomadas sem a necessidade de um diálogo prévio com todas as partes por elas afetadas. Consequentemente, uma predisposição política que acaba por sistematicamente favorecer certos grupos enquanto prejudica outros é gerada.

Já o segundo problema encontrado pelas teóricas políticas feministas baseia-se na crítica aos limites do exclusivo enfoque individualista do liberalismo em lidar com desigualdades estruturais como a de gênero, pois tal enfoque inviabiliza tanto a identificação quanto a possibilidade de lidar com tais desigualdades em âmbito institucional. Em síntese, argumenta-se que tentar lidar com desigualdades estruturais que afetam grupos sociais através de um enfoque no indivíduo isoladamente não dá conta de gerar ações políticas institucionais que 
respondam de maneira adequada às complexidades envolvidas nas desigualdades de gênero (PHILLIPS, 1993, 1995).

Ao incluir a representação direta de sujeitos coletivos e uma dimensão estrutural para enfrentar o problema das desigualdades, as políticas de diferença visam ampliar as atéentão limitadas possibilidades de trabalhar institucionalmente contra os mecanismos geradores de tais desigualdades. Sob o ponto de vista de teóricas políticas feministas, a politização de diferenças é vista como uma maneira de colocar o funcionamento das instituições sociais sob escrutínio crítico, além de permitir o combate a desigualdades com base em gênero a partir da própria esfera institucional.

Isso posto, de que forma o essencialismo poderia comprometer tal intuito? Se a estabilização de sujeitos coletivos implica afirmar a preexistência de determinados interesses que caracterizam o grupo já de antemão, qualquer contestação que possa ameaçar tal estabilidade se torna inadmissível. Assim, a possibilidade de se gerar um diálogo potencialmente transformador através da inclusão de políticas de diferença na esfera pública pode ficar comprometida: o mesmo essencialismo que torna possível a estabilização de sujeitos coletivos visando o questionamento dos mecanismos de reprodução das desigualdades estruturais na esfera pública pode acabar comprometendo a possibilidade de que tal questionamento venha a ser verdadeiramente transformador, uma vez que a suposta preexistência de determinados interesses de grupo não pode se tornar objeto de debate na esfera pública sem que a própria politização dos atores coletivos seja também posta em xeque.

$\mathrm{Na}$ ausência de condições propícias para que o debate público seja capaz de explicitar os mecanismos de perpetuação de desigualdades, ocasionada pelo processo de essencialização, o potencial transformador originalmente almejado pela politização de diferenças pode inclusive vir a ser anulado, reduzindo a inserção de entidades coletivas na esfera pública a um mero reconhecimento simbólico e formal de sua presença na sociedade.

Igualmente, a presença de fortes restrições aos termos em que se dá o debate na esfera pública, advinda de uma possível imposição de supostos interesses 'cristalizados' dos grupos politizados na esfera pública, pode transformar as políticas de diferença em um pluralismo de grupos de interesse, que estimula a fragmentação social. Nesse caso, também ocorre uma inversão do sentido original do projeto de politização de diferenças: em vez de eliminar a parcialidade da 
esfera pública, as políticas de diferença passariam a introduzi-la sob a forma de identidades e interesses cristalizados.

Portanto,maisdoqueevitarosnegativos 'efeitoscolaterais' queacompanham 0 processo de essencialização - como estereotipagem e homogeneização dos membros de um grupo -, o principal desafio que o essencialismo coloca para os defensores das políticas de diferença é o perigo de gerar falta de abertura para um debate que seja capaz de efetivamente questionar as estruturas de desigualdade que regem o fazer político. Isso porque o essencialismo, como vimos, pode comprometer o principal propósito das políticas de diferença, que é o de provocar um debate público que viabilize denunciar e minar a parcialidade na esfera pública, condição sine qua non para a transformação de estruturas de dominação no seio do fazer político e a plena realização de justiça social.

A fim de provar que a inclusão de representação de grupos em desvantagem social no processo de deliberação política não leva à restrição, mas sim à ampliação do debate sobre a formação de desigualdades estruturais, os defensores das políticas de diferença precisam demonstrar que identidades e interesses grupais não são dados ou identificáveis anteriormente ao processo de politização, senão que se constroem e emergem durante o próprio processo de debate e deliberação na esfera pública.

\section{É POSSÍVEL MANTER GÊNERO ENQUANTO CATEGORIA TEÓRICA VIÁVEL SEM INCORRER EM ESSENCIALISMO?}

A estratégia tradicional usada pelas teóricas políticas feministas a fim de sobrepujar a crítica do essencialismo tem se concentrado em apresentar uma conceitualização não essencialista de grupos sociais ${ }^{3}$. Tal estratégia parece denotar que uma definição não essencialista do grupo social em questão garantiria que o projeto de politização de diferenças tenha, por sua vez, consequências não essencialistas.

A despeito das inúmeras tentativas de formular uma definição não essencialista de entidades coletivas, os críticos seguem argumentando que a conceitualização de grupos sociais oferecida pelos defensores das políticas de

\footnotetext{
${ }^{3} 0$ desenvolvimento de um conceito não essencialista de grupos sociais pode ser encontrado, por exemplo, no trabalho de Iris Marion Young (1989, p. 250-74; 1990; 1994, p. 713-38; 1999, p. 415$21 ; 2000)$.
} 
diferença segue com uma forte dependência de certo 'senso de identidade' compartilhado por seus membros, o que bastaria para acusar a presença de essencialismo, considerando que "qualquer conceitualização [de identidades] conduz as impressões e o fluxo de experiências a uma ordem que unifica e compara", "construindo sistemas totalizadores" que "negam ou reprimem as diferenças" (YOUNG, 1990, p. 98-9)4.

Young (1994, p. 723), com base na consideração de Jean-Paul Sartre sobre o fenômeno de coletividade serial, procura até mesmo proporcionar "uma maneira de pensar mulheres enquanto um coletivo social sem requerer que todas as mulheres tenham atributos em comum ou se encontrem na mesma situação". Ela argumenta que o fato de as mulheres compartilharem de uma perspectiva diferenciada - devido a seu posicionamento social e relações institucionais "que condicionam suas oportunidades e expectativas para a vida” (YOUNG, 2000, p. 97) enquanto mulheres - não compromete a construção da própria identidade, a qual continua sendo formada ativamente pelo indivíduo: "Atores individuais constroem suas próprias identidades, mas não sob condições que foram por eles escolhidas" (YOUNG, 2000, p. 99). Através dessa estratégia, Young implicitamente sugere que os interesses de grupo não são anteriores ao processo de diálogo na esfera pública, senão constituídos por este.

No entanto, parece que tais tentativas de conceitualizar diferenças de uma maneira não essencialista não estão completamente imunes à crítica do essencialismo. Seyla Benhabib (2002, p. 137), por exemplo, segue rejeitando as políticas de diferença, acusando Young de introduzir essencialismo com uma nova 'roupagem': prendendo indivíduos "nas refrações perspectívicas de seu posicionamento social"'s.

\footnotetext{
${ }^{4}$ Nesta passagem, Young lança mão da crítica à lógica da identidade desenvolvida por Derrida com o objetivo de criticar o ideal de imparcialidade. As dificuldades relacionadas às tentativas de teorizar identidades levaram muitas teóricas políticas feministas a abandonar completamente o uso do conceito de gênero (MOI, 1999). Mais sobre a discussão a respeito da perda de gênero enquanto categoria teórica viável e as possibilidades de ação política efetiva, (WELDON, 2007, p. 280-8; BARRETT ; PHILLIPS, 1992).

${ }^{5}$ Michael R. James e Johnny Goldfinger tentam resolver esse problema através do conceito de diferença estatística de probabilidade: embora os indivíduos que compõem um grupo social não compartilhem todos da mesma experiência, há, no entanto, maior "probabilidade estatística de haver um membro do grupo compartilhando daquela determinada perspectiva" (JAMES; GOLDFINGER, 2005).
}

Do PROBLEMA DO ESSENCIALISMO A OUTRA MANEIRA DE SE FAZER...

L. TOSOLD $\bullet 173$ 
Se tentar conceitualizar identidades de maneira não essencialista já é uma tarefa difícil no campo teórico, na prática política, durante o processo de inclusão de representação de grupos na esfera pública, é - segundo os críticos - certamente muito mais fácil incorrer em essencialismo (BARRY, 2002, p. 204-38). Conforme afirma Benhabib (1999, p. 405), "enquanto rejeitam o essencialismo cultural estrategicamente, [os defensores das políticas de diferença] são frequentemente comprometidos com isso "politicamente".

Dessa maneira, a despeito de todas as tentativas de se conceitualizar grupos sociais de maneira não essencialista, qualquer apelo em favor da inserção de sujeitos coletivos na esfera pública está, a princípio, sujeito à crítica do essencialismo. Como aponta Moya Lloyd (2005, p. 56), "implícito nesse argumento contra sujeitos estáveis enquanto base para a formação de políticas de identidade encontra-se a hipótese de que qualquer forma de políticas de diferença está fadada ao fracasso".

Não surpreende, portanto, que o insucesso na estratégia de tentar conceitualizar grupos sociais de maneira não essencialista tenha arrefecido 0 entusiasmo pelo projeto de politização de diferenças em teoria política. Sem a superação da crítica do essencialismo, o potencial de questionamento efetivo e transformador das desigualdades sociais através das políticas de diferença parece haver-se perdido. Mais do que isso, muitos críticos ainda argumentam que as políticas de diferença poderiam conduzir ao oposto do inicialmente pretendido, contribuindo paradoxalmente para ampliar a percepção do que nos divide na sociedade, reforçar estereótipos e hostilidades e, até mesmo, gerar cisões entre grupos inexistentes até então, resultando em fragmentação social e acréscimo de intolerância.

Considerando esse cenário, como evitar abrir mão de gênero enquanto categoria teórica viável? Na dificuldade em se superar o problema do essencialismo através da conceitualização de grupos sociais, a estratégia entre teóricas políticas feministas passou a ser a de abraçar o essencialismo para fins políticos. Ou seja, em vez de tentar superar o problema do essencialismo, passou-se a assumi-lo como uma "estratégia necessária” (BRAIDOTTI, 1994, p. 177 apud LLOYD, 2005, p. 56). Lloyd (2005, p. 63-64), por exemplo, justifica o uso de tal estratégia alegando que, em determinados momentos históricos, essencialismo é "o único modo autêntico de atuação política". Como forma de abrir caminho para a ação política com base em gênero ou qualquer outra categoria geradora de desigualdades estruturais, essencialismo passa, então, a ser estimado como uma possível estratégia. 
Essa abordagem sugere que os 'benefícios' em permitir a inserção de um sujeito coletivo na esfera pública contrabalançam os 'efeitos negativos' gerados pelo essencialismo que decorre de seu processo de estabilização para fins políticos. No entanto, apesar dessa estratégia conferir grau de legitimidade a certas consequências possíveis do essencialismo, como a estereotipagem e a homogeneização dos membros de um grupo em condições históricas não ideais, acaba por não considerar o principal desafio que o essencialismo coloca à politização de diferenças que, conforme visto, consiste em como evitar a imposição de restrições a um debate potencialmente transformador das desigualdades estruturais na esfera pública.

0 essencialismo estratégico, portanto, ainda que tenha o mérito de colocar em questão a estagnação política motivada pela crítica do essencialismo, ébaseado em um entendimento superficial das consequências do essencialismo para 0 projeto de politização de diferenças. Somente uma abordagem que leve em conta a possibilidade de tal fenômeno impedir o debate desmascarador da parcialidade e transformador das desigualdades na arena política pode assegurar que a inserção de sujeitos coletivos levará à ampliação de justiça social em vez de um pluralismo de grupos de interesse ou o mero reconhecimento simbólico de identidades na esfera pública.

\section{RETOMANDO O POTENCIAL TRANSFORMADOR DAS POLÍTICAS DE DIFERENÇA}

Em contraste com o desenvolvimento do debate sobre políticas de diferença na teoria política feminista discutido até então - que, conforme visto, tem enfocado exclusivamente em como conceitualizar grupos em processo de politização de maneira não essencialista -, a parte final deste artigo propõe retomar como perspectiva de análise o vínculo entre as políticas de diferença e a questão das desigualdades estruturais, que acabou sendo ofuscado nesse debate. Em outras palavras, o foco excessivo na conceitualização de grupos sociais como solução para a crítica do essencialismo levou a que a politização de diferenças deixasse de ser associada ao projeto político mais amplo ao qual originalmente se vincula. Assim, em vez de provocar o questionamento dos mecanismos através dos quais se dá o próprio fazer político - revelando como a perpetuação de desigualdades estruturais opera dentro do paradigma político dominante e propondo outra maneira de se fazer política -, as políticas de diferença foram reduzidas a uma 
espécie de instrumento de ação entre outros, como se fossem medidas que podem ou não vir a ser adaptadas a um modo de funcionamento político já estipulado de antemão.

Ora, segundo os críticos das políticas de diferença, uma mera definição não essencialista de grupos sociais não elimina a possibilidade de essencialismo na prática política (BARRY, 2002, p. 211; BENHABIB, 1999, p. 405). Tal argumento, por si só, sugere a necessidade de perscrutar criticamente a configuração da esfera política através da qual as entidades coletivas são politizadas. No entanto, tais críticos continuam rejeitando a politização de diferenças exclusivamente com base na suposta impossibilidade de definir grupos sociais sem incorrer em essencialismo. Seu argumento, análogo ao dos defensores das políticas de diferença, permanece restrito ao paradigma da relação entre essencialismo e conceitualização de diferenças. Como consequência, tanto a estrutura política através da qual os atores coletivos vêm a ser politizados quanto as desigualdades estruturais dela advindas permanecem inquestionadas. No lugar de se vislumbrar novos horizontes para um fazer político transformador através da politização de diferenças, acaba-se por reificar diferenças e identidades enquanto categorias problemáticas de análise. Com o ônus em relação ao problema do essencialismo recaindo exclusivamente sobre a definição de diferenças ou identidades coletivas, deixa-se de questionar por que essas categorias de análise permanecem sendo tão estranhas e alheias ao próprio fazer político.

Assim, conclui-se que a inserção de sujeitos coletivos na esfera pública não pode ser adequadamente avaliada em relação à crítica do essencialismo sem levar em consideração as implicações políticas mais amplas do projeto de politização de diferenças. As políticas de diferença não devem ser entendidas como políticas públicas isoladas em uma configuração política já preestabelecida de antemão, visto que requerem outro fazer político que seja capaz de superar desigualdades estruturais. A fim de compreender como o processo de politização de diferenças está transformando - e não inviabilizando - o funcionamento da comunidade política e a possibilidade de efetiva justiça social, é fundamental perceber 0 essencialismo não simplesmente como problema em si, mas principalmente como indicador de desafios importantes para um novo fazer político que se pretende configurar, capaz de dar conta da complexidade de desigualdades estruturais que, até então, estiveram além do alcance do projeto liberal.

À luz da perspectiva de análise aqui proposta, serão examinados, por fim, os projetos políticos de Anne Phillips e Iris Young. Considerando que ambas 
denunciam o ideal liberal de imparcialidade na esfera pública e se preocupam em manter a inserção de atores coletivos como forma de possibilitar ação política contra desigualdades estruturais institucionalizadas sem descuidar dos desafios apresentados pelo essencialismo, faz-se interessante evidenciar os caminhos que elas apontam para reconfigurar a esfera política de maneira transformadora.

Phillips, consciente do problema do essencialismo, reconhece que Young, como ela, "rejeita explicitamente a ideia de que identidades de grupos são definidas por algum conjunto essencialista de atributos comuns" e está ciente de que "a maioria das pessoas tem múltiplas identificações de grupos, e que é característica dos grupos se formarem e se esvaírem" (PHILLIPS, 1993, p. 96). No entanto, Phillips critica a proposta política de Young, argumentando que ela advoga uma versão mais 'radical' ('strong') de institucionalização de sujeitos coletivos. Mas em que consiste o projeto político de Young? Em suas próprias palavras:

[...] a representação de grupos envolve mecanismos institucionais e recursos públicos para apoiar (1) a auto-organização dos membros do grupo, de maneira que eles atinjam o fortalecimento [empowerment] coletivo e um entendimento reflexivo de sua experiência e interesses coletivos no contexto social em que vivem; (2) a análise e a geração de propostas políticas do grupo em contextos institucionalizados, em que os tomadores de decisões [decisionmakers] são obrigados a mostrar que sua deliberação levou em conta as perspectivas do grupo; e (3) o poder de veto do grupo em relação a políticas específicas que o afetam diretamente, como políticas de direitos reprodutivos para mulheres e políticas agrárias em reservas indígenas (YOUNG, 1990, p. 184).

Dados os detalhes do projeto político de Young, quais são, segundo Phillips, seus pontos problemáticos? Ela aponta dois principais fatores. Em primeiro lugar, a demanda pelo uso de recursos públicos, ou status especial, proposta por Young, pois isso levaria a que se focasse excessivamente em definir quais grupos sociais são politicamente relevantes, estimulando essencialismo por "congelar o que é múltiplo e alterar identidades de maneira a fixar limites severos à noção de representação de grupos" (PHILLIPS, 1995, p. 54-5). E, em segundo lugar, a dificuldade em estabelecer mecanismos de accountability a fim de assegurar que todos os membros do grupo estarão sendo de fato representados (PHILLIPS, 1993, p. 97-8).

A alternativa a essa versão 'radical' de institucionalização de diferenças é o que Phillips denomina versão 'branda' ('soft'), capaz, segundo ela, de evitar 0

Do PRoblema Do ESSENCIALISMO A OUTRA MANEIRA DE SE FAZER...

L. Tosold $\bullet 177$ 
problema do essencialismo enquanto se mantém a presença institucional de atores coletivos com o objetivo de lidar com as desigualdades estruturais: a representação proporcional. Phillips argumenta em favor da combinação de uma 'política de presença' ('politics of presence', referente a quem é representado) com uma 'política de ideias' ("politics of ideas', referente a o que é representado), ou seja, "a inclusão de membros de grupos atualmente sub-representados na política”, mas não com o propósito de defender interesses coletivos particulares e já de antemão cristalizados, senão o de possibilitar que os integrantes do grupo "lidem mais diretamente com o debate e as decisões políticas” (PHILLIPS, 1995, p. 167).

Phillips parte da premissa de que certos grupos sociais são sub-representados politicamente como resultado de uma desigualdade social decorrente de fatores bistóricos. Ela propõe, então, que membros de grupos marginalizados sejam incluídos no processo de deliberação política com o objetivo de 'equalizar as desigualdades' na representação. A forma clássica de implementação dessa proposta seria através da inserção de cotas. 0 cerne da representação proporcional de Phillips é, portanto, procurar não vincular os membros do grupo à defesa de interesses coletivos supostamente preexistentes. Em vez disso, ela busca "uma noção mais exploratória de possibilidades até então silenciadas e de ideias que temos de nos esforçar para conseguir expressar" (PHILLIPS, 1993, p. 70), o que procura evitar o problema do essencialismo por associar a formação de interesses e a expressão de perspectivas ao próprio processo político.

Com essa estratégia, Phillips procura transformar a noção de interesses de grupos. Levando em conta a pluralidade de ideias entre os membros de um grupo, a busca pela convergência de interesses não é possível nem desejável. Assim, ela dissocia a noção de interesses de grupos de seu entendimento comum enquanto um conjunto de "prioridades e metas" (PHILLIPS, 1995, p. 68). Em seu lugar, Phillips (1995, p. 176) introduz o conceito de perspectiva: "um senso de questões ainda não precisamente delineadas e prioridades a serem definidas".

Essa estratégia que migra de 'interesses' para 'perspectivas' é análoga ao próprio conceito de perspectiva desenvolvido por Young no processo de legitimar mulheres como coletivo social, conforme visto na seção II deste artigo. Mas, em contraste com Young, Phillips procura viabilizar a representação proporcional sem institucionalizar a representação de grupos. Como resultado, Phillips espera garantir a inclusão de grupos até então marginalizados do fazer político evitando as dificuldades inerentes ao processo de accountability que ela identifica no projeto político de Young. 
Neste ponto, no entanto, uma questão importante emerge: se os membros de um grupo são caracterizados por uma pluralidade de posições e interesses que podem até mesmo ser conflitantes entre si, seria ainda possível defender a existência de uma perspectiva de grupo dentro do modelo político proposto por Phillips, em que se sugere que os membros de um grupo devam ser incluídos sem prévia organização e sem compromisso de accountability com o grupo? Phillips argumenta que "a variedade de interesses entre as mulheres não refuta a reivindicação de que os interesses são perpassados pela categoria de gênero" e ilustra essa ideia com um exemplo: "que certas mulheres optem por não ter filhos não faz da gravidez uma ocorrência neutra em termos de gênero" (PHILLIPS, 1995, p. 68). Em outras palavras, o projeto de politização de diferenças de Phillips não pode, a princípio, oferecer nenhuma garantia de que "as necessidades e os interesses das mulheres serão considerados", visto que, a fim de evitar o problema do essencialismo, "faz-se necessário operar em um campo de probabilidades em vez de certezas" (PHILLIPS, 1995, p. 82). No entanto, a inserção de membros de grupos até então excluídos da esfera pública promete ampliar a probabilidade de que a perspectiva do grupo seja politicamente representada, influencie políticas públicas, levante novos tópicos de interesse e leve, assim, a maior justiça e transformações sociais no quadro das desigualdades estruturais.

\section{CONSIDERAÇÕES FINAIS: UM BALANÇO DOS PROJETOS políticos de Anne Phillips e Iris Marion Young}

Apesar de a proposta de Phillips parecer bastante razoável, ela engendra pelo menos dois aspectos problemáticos. Em primeiro lugar, embora seu projeto político possa funcionar para categorias de formação de grupos relativamente não controversas, como gênero, o problema do essencialismo retorna na tentativa de inserção de membros de grupos formados por categorias sociais mais complexas, como pode ser, por exemplo, o caso de raça em determinados contextos sociais. Isso porque o modelo de Phillips pressupõe o que ela originalmente procurou evitar: uma identificação social não controversa de quem pertence ou não a determinado grupo como pressuposto para que a representação proporcional possa vir a ter lugar.

Ora, não é possível nem desejável que, para fins de representação proporcional, a identificação de membros de grupos com base em categorias sociais mais complexas preceda um amplo debate na esfera pública que vise identificar 
as formas como tais mecanismos de exclusão operam e de que maneira atingem os indivíduos em determinado contexto social. Isso envolveria a necessidade de incentivo para que potenciais atores sociais possam se auto-organizar a fim de iniciar o debate que levaria à politização de um novo sujeito coletivo, tal qual propõe Young e é, de antemão, rejeitado por Phillips com base na crítica do essencialismo.

Em segundo lugar, e ainda mais importante, ao acreditar que as desigualdades sociais existentes decorrem de fatores históricos extrínsecos ao próprio mecanismo de funcionamento político, as políticas de diferença são, dentro do projeto de Phillips, exclusivamente encaradas como instrumentos ‘equalizadores de desigualdades', uma espécie de corretivo provisório, necessárias até que a representação proporcional possa dar-se por si mesma na sociedade. Em outras palavras, as políticas de diferença são 'adaptadas' a um paradigma político que parece não haver ainda esgotado suas possibilidades de gerar justiça social. Dessa maneira, Phillips acaba por eclipsar o vínculo que as políticas de diferença têm com a crítica ao liberalismo, retomando-o acriticamente como paradigma político ideal ao não permitir que surja, através das políticas de diferença, um questionamento mais amplo do funcionamento do próprio fazer político como gerador e reprodutor de desigualdades estruturais.

Já Young, em contraste, acredita que as desigualdades sociais não decorrem apenas de fatores históricos, mas são também imanentes ao processo de funcionamento político. Em suas palavras:

A inclusão de grupos diferenciados é importante não apenas como meio de demonstrar respeito mútuo e de garantir que todos os interesses legítimos na comunidade política tenham expressão, ainda que tais razões sejam fundamentais para a inclusão democrática. A inclusão tem duas funções adicionais. Primeiro, a de motivar os participantes no debate político a transformar a mera expressão de interesses particulares em reivindicações por justiça. Segundo, a de maximizar o conhecimento social [social knowledge] disponível a uma audiência democrática, de maneira que os cidadãos se tornem mais inclinados a tomar decisões justas e sábias (YOUNG, 2000, p. $115)$.

Esse excerto denota que Young, de fato, preocupa-se não só com a "equalização do acesso de indivíduos às elites políticas" (YOUNG, 1993, p. 101), mas também com a possibilidade de transformação na maneira de fazer política 
de modo a transcender o enfoque individualista do liberalismo e desmascarar a parcialidade na esfera pública através da inserção de diferentes perspectivas coletivas. Para tanto, Young posiciona a expressão de diferenças como o próprio cerne da vida política, transformando-a em recurso para o fazer político:

Inclusão não deve simplesmente significar a igualdade formal e abstrata de todos os membros da comunidade política enquanto cidadãos. Antes, inclusão significa reconhecer explicitamente diferenciações sociais e divisões, assim como encorajar grupos em diferentes posições a dar voz a suas necessidades, seus interesses e suas perspectivas sobre a sociedade, respeitando as condições de razoabilidade [reasonableness] e publicidade (YOUNG, 2000, p. 119).

Ao conferir centralidade às políticas de diferença enquanto recurso para um novo fazer político, Young reivindica que a inserção de diferenças na arena pública não é apenas inevitável: é também desejável. No projeto político de Young, portanto, as diferenças deixam de ser percebidas como elementos estranhos a serem inseridos em uma prática política que delas prescinde ou como algo a ser transcendido assim que os mecanismos de correção de parcialidade institucional que hoje afetam certos grupos não sejam mais necessários. Tal perspectiva abre a possibilidade de um questionamento mais amplo do próprio funcionamento político, visando que este seja transformado de maneira que a politização de diferenças possa configurar-se da melhor forma possível, não apenas livre de essencialismos, mas também capaz de eliminar as desigualdades estruturais e gerar resultados justos na arena política.

A mudança de foco de diferenças enquanto categoria problemática para a exploração de novas formas de fazer política que possam dar conta das demandas do processo de politização de diferenças, que ocorre dentro do projeto político de Young, explica seu crescente interesse por métodos de funcionamento do processo de deliberação. Isso fica evidente em sua tentativa de desenvolver uma "democracia comunicativa" ("communicative democracy") com base no modelo habermasiano de democracia deliberativa (YOUNG, 1996, p. 120-35), em que procura refinar os procedimentos de deliberação a fim de eliminar a parcialidade da esfera pública através de uma plena e não essencializada expressão de diferentes grupos sociais, bem como enfatizar que a justiça só poderá ser atingida quando a expressão de diferenças passar a ser o fundamento do processo de deliberação política. 
Há, evidentemente, uma série de críticas relevantes ao projeto político de Young acima explicitado, que demandariam um espaço de discussão que extrapola a proposta do presente artigo. Debate-se, por exemplo, se seu projeto engendra de fato um questionamento genuíno e transformador do liberalismo ou, contrariamente, esconderia um liberalismo 'com nova roupagem', aproximandose do multiculturalismo. Ainda mais importante, argumenta-se também que 0 crescente enfoque nos mecanismos de deliberação acaba por afastar o projeto de Young do enfrentamento da questão central das desigualdades sociais ${ }^{6}$. No entanto, e mesmo de acordo com tais críticas, o fato de Young haver abraçado a ideia de que a politização de diferenças requer um questionamento mais amplo do fazer político tem, em si, enorme mérito. Recuperar a perspectiva de que é possível vislumbrar novos caminhos para a construção de verdadeira justiça social, em um momento em que as políticas de diferença são descreditadas em prol de um fazer político que, antes, provou não ser capaz de dar conta da persistência de desigualdades estruturais na sociedade, torna-se não somente válido, mas essencial.

\section{REFERÊNCIAS}

BARRETT, Michèle; PHILLIPS, Anne (Org.). Destabilizing theory: contemporary feminist debates. Cambridge: Polity, 1992.

BARRY, Brian. Second thoughts: and some first thoughts revived. In: KELLY, Paul (Org.). Multiculturalism reconsidered. Cambridge: Polity, 2002. p. 204-38.

BENHABIB, Seyla. The liberal imagination and the fourdogmas of multiculturalism. The Yale Journal of Criticism, Baltimore, v. 12, n. 2, p. 401-413, 1999.

(Org.). The claims of culture: equality and diversity in the global era. Princeton: Princeton University Press, 2002.

BRAIDOTTI, Rosi. Nomadic subjects: embodiment and sexual difference in contemporary feminist theory. New York: Columbia University Press, 1994.

FUSS, Diana. Essentially speaking: feminism, nature and difference. London: Routledge, 1989.

GOLDFINGER, Johnny; JAMES, Michael R. Rethinking social group perspective. In: ANNUAL MEETING OF THE AMERICAN POLITICAL SCIENCE ASSOCIATION, 2005, Washington. Paper... Washington, 2005.

${ }^{6}$ A respeito dessa crítica, cf. o artigo de Luis Felipe Miguel (2010). 
KYMLICKA, Will. Multicultural citizenship. Oxford: Oxford University Press, 1996. LLOYD, Moya. Beyond identity politics: feminism, power \& politics. London: Sage, 2005.

MIGUEL, Luis Felipe. Perspectivas sociais e dominação simbólica: a presença política das mulheres entre Iris Marion Young e Pierre Bordieu. Revista de Sociologia e Política, Curitiba, v. 18, n. 36, p. 25-49, 2010.

MOI, Toril. What is a woman? and other essays. Oxford: Oxford University Press, 1999.

PHILLIPS, Anne. Universal pretentions in political thought. In: BARRETT, Michèle; PHILLIPS, Anne (Org.). Destabilizing theory: contemporary feminist debates. Cambridge: Polity, 1992. p. 10-30. . Democracy and difference. Cambridge: Polity, 1993.

. The politics of presence: the political representation of gender, ethnicity and race. Oxford: Oxford University Press, 1995.

TAYLOR, Charles. The politics of recognition. In: GUTMANN, A. (Org.). Multiculturalism and 'the politics of recognition'. Princeton: Princeton University Press, 1992. p. 25-73.

WELDON, S. Laurel. Difference and social structure: Iris Young's critical social theory of gender. Constellations, 0xford, v. 14, n. 2, p. 280-88, 2007.

YOUNG, Iris Marion. Polity and group difference: a critique of the ideal of universal citizenship. Ethics, Washington, v. 99, n. 2, p. 250-274, 1989.

Press, 1990.

.Justice and the politics of difference. Princeton: Princeton University

. Gender as seriality: thinking about women as social collective. Signs, New Brunswick, v.19, n. 3, p. 713-738, 1994.

. Communication and the other: beyond deliberative democracy. In: BENHABIB, Seyla (Org.). Democracy and difference: contesting the boundaries of the political. Princeton: Princeton University Press, 1996. p. 120-35.

. Ruling norms and the politics of difference: a comment on Seyla Benhabib. The Yale Journal of Criticism, Baltimore, v. 12, n. 2, p. 415-421, 1999. . Inclusion and democracy. Oxford: Oxford University Press, 2000. 